\title{
O PENSAMENTO E A MÁQUINA
}

\author{
Duogo Furtado *
}

Uma das mais velhas aspirações do homem, revelada sob variadas formas, é a da criação de mecanismos automáticos capazes de o substituírem em muitas das suas actividades. $O$ grau extremo destas aspirações tem consistido no criar máquinas de pensar e até seres autómatos e pensantes. Sendo impossível fazer aqui a completa história desta aspiração humana, não quero deixar de lembrar algumas das suas etapas fundamentais.

Assim, vemos na antigüidade grega a Platão, preocupado em estudar os mecanismos do pensamento e em obter uma máquina capaz de os substituir. Na Idade Média, temos notícia de Raimundo Lulio, estranha figura de filósofo, sábio e místico — a quem chamaram o doctor illuminatus - autor de uma vasta obra cuja parte mais original é a tentativa da criação de um mecanismo de raciocínio lógico. Este mecanismo, verdadeiro antepassado das máquinas de calcular que obedecem ao princípio da analogia, compunha-se de três círculos girando uns sobre os outros, cada um dêles correspondendo a um aspecto da lógica. Os resultados absurdos da máquina do doctor illuminatus não foram estranhos ao seu trágico fim, lapidado numa praça de Bougie.

Entramos na Renascença, e depara-se-nos a gigantesca figura de Leonardo da Vinci - cujo centenário estamos celebrando - porventura a maior e a última encarnação do homo universalis, a quem o problema dos autómatos muito preocupou. Em Leonardo não havia, na criação dos autómatos, o objectivo de curiosidade ou de demonstração filosófica que vemos noutros; a sua finalidade, puramente humanitária, era a de poupar o homem, escravo da vida, aos trabalhos que esta lhe impunha. Em tôrno do problema dos autómatos, Leonardo criou um sem número de máquinas úteis. muitas das quais só ùltimamente foram sendo desenterradas, e que são verdadeiras precursoras das maiores descobertas modernas.

Conferência pronunciada na Associação Paulista de Medicina, durante a I Jornada Médica Luso-Brasileira, em 11 setembro 1952.

* Professor da Faculdade de Medicina de Lisboa. Director do Serviço de Neurologia dos Hospitais Civis de Lisboa. 
Mais tarde, vemos Pascal procurando criar uma máquina de calculär, e Leibniz filosofando sôbre a concepção de um mecanismo automático de pensar. Vemos no século XVIII os relojoeiros suíços criarem pequenos autómatos perfeitíssimos, provas da inexcedível técnica dessa indústria naquele país, e que ainda hoje constituem o nosso espanto. E assistimos à transposição para a literatura, dessa aspiração de criar autómatos, cuja expressão mais conhecida é talvez a de Copélia, dos Contos de Hoffmann, que todos nós lemos, ouvimos cantar e vimos até dançar, na plástica admirável de Moira Shirer.

Mas, na realidade, a primeira máquina de calcular só surge em meados do século XIX, quando o matemático Babbage aplica ao problema aquilo a que chamamos hoje o princípio da analogia, criando os discos multiplicadores. Apresentada na Exposição Universal de 1851, a máquina de Babbage foi tendo imitadores, mas o progresso era lento.

$\mathrm{Na}$ realidade, duas grandes aquisições deram lugar a um salto brusco para a realização desta velha aspiração da humanidade: a descoberta dos mecanismos de auto-regulação inversa. chamados pelos anglo-saxões de feedback, e o advento da era electrónica. Lembrarei que a descoberta dos mecanismos auto-reguladores é muito velha, devendo-se a Watt, quando pôs em prática a válvula de comando da máquina de vapor e o leme automático dos navios; o alcance das descobertas de $W$ att passou, pode dizer-se, despercebido e só quando Maxwell mostrou a filiação nelas de todos os actuais mecanismos de feed-back, foi possível realizar a sua extensão. A aplicação à ciência e à indústria das válvulas termiónicas de vácuo, abriu a era da electrónica. Os progressos feitos desde então caracterizaram-se por uma rapidez extraordinária.

Dos mecanismos automáticos primitivos, rudimentares, chegamos ràpidamente aos gigantescos cérebros electrónicos, do tipo do Eniac ou dos Ferranti, de que dentro em pouco falarei repetidamente. Chegamos ao predictor do canhão anti-aéreo, mecanismo espantoso, cujas aptidões apresentarei agora como exemplo que permita compreender a extensão do problema. Foi, com efeito, nas máquinas de guerra que mais imediata e perfeitamente foram aplicadas as modernas aquisições da física: detecção automática pelo radar, torpedos auto-comandados, avióes sem piloto e armas anti-aéreas de inverossímil perfeição.

A peça anti-aérea de médio e grande calibre é tele-comandada, isto é, aponta e dispara sob acção dum mecanismo electrónico, colocado a distância da peça e que é o seu verdadeiro cérebro. Este mecanismo, altamente complexo, tem o nome de predictor e está elèctricamente ligado, tanto à peça como a um gerador comum. A peça encontra-se montada sôbre bombas de óleo, as quais são accionadas por sinais eléctricos transmitidos do predictor, imprimindo à peça todos os movimentos possíveis, necessários para a pontaria, e determinando oportuna e repetidamente os disparos. 
O predictor é uma verdadeira máquina de calcular, à qual se fornecem apenas dois dados: a distância aproximada a que está o avião, e a sua focagem numa ocular anexa; ao que parece, em peças mais modernas, a própria célula fotoeléctrica do predictor, accionada por radar, procura e foca o avião a abater. Depois, o predictor faz tudo, e êste tudo é muito. Os cálculos necessários para atingir o avião são complicadíssimos. Em primeiro lugar, como é intuitivo, há que calcular o ponto antecipado na trajectória do avião que se deve visar, antes de o avião o atingir. Este pode deslocar-se segundo as três coordenadas do espaço, e, assim. o predictor tem de calcular não só o ângulo de alça, que cobre duas destas coordenadas, altura e profundidade, como também o desvio horizontal. Os predictores modernos vão ainda mais longe porque adicionam a êstes dados o cálculo das probabilidades que tem o piloto de executar esta ou aquela manobra de fuga ou finta para iludir.

Ora, êstes cálculos e correç̧ões são introduzidos sôbre o circuito principal, que é neste caso aquêle que faz disparar a peça, por uma série de circuitos electrónicos correctivos, caminhando no sentido inverso (inverse feed-back). Consoante as necessidades da exactidão do tiro, umas vêzes os circuitos correctivos tendem a aproximar a pontaria do alvo (feed-back negativo), outras vêzes a afastá-la (feed-back positivo). Assim, a peça anti-aérea actua como um verdadeiro mecanismo auto-governado: não só actua automàticamente, como faz a recolha das informações que permitem conhecer em que proporção a acção em curso difere da acção a efectuar, e portanto corrigir pelos circuitos de feed-back, os erros existentes.

A eficácia do mecanismo servo-comandado da peça anti-aérea é extraordinária, muito além daquilo que geralmente se julga. Numa estatística recolhida na "Anti-aircraf Review" americana, contendo os resultados da última fase da II Grande Guerra, verifica-se que, por 100 aviões inimigos abatidos, cêrca de 60 o eram pelas peças anti-aéreas, 10 apenas pelos caças e os 30 restantes perdiam-se por causas diversas. Em abono desta eficácia é interessante lembrar também que, numa noite em que sôbre Londres foram lançadas 100 bombas $\mathrm{V}_{2}$, apenas duas atingiram a cidade, visto as outras 98, localizadas pelo radar, terem sido destruídas pelo fogo antiaéreo. As últimas informações da gọerra da Coréia depõem no mesmo sentido: $80 \%$ dos avióes ali abatidos são-no pelas peças anti-aéreas. Assim, a eficácia do funcionamento quase "cerebral" do predictor, fica largamente demonstrada.

0 advento de semelhantes mecanismos servo-comandados, de tão grande perfeição, trouxe consigo novos problemas, e até a criação de uma nova disciplina científica. Wiener, matemático e filósofo, criou o têrmo de cibernéticas, derivado de leme, em grego, para designar esta nova ciência que estuda as comunicações, isto é, transmissão de sinais, nas máquinas e no homem. 
Sábios eminentes, como McCulloch, Ashby, Neumann, Grey Walter, Gastaut e muitos outros apareceram interessados nesta disciplina científica comparativa, que procura afinal reduzir o homem às proporções de máquina. Não se trata já apenas de criar cérebros electrónicos, mas de demonstrar que o do homem não é mais do que uma edição aperfeiçoada daqueles que êle próprio já aprendeu a criar. E as cibernéticas aparecem de súbito na ciência e na filosofia como a solução de um problema que parecia eterno, como "a única ponte real entre a psique e o soma", segundo afirma McCulloch.

Eis, pois, ao que visa a presente conferência: exposição sumária dos dados do problema e crítica teórica das ilações que dêsses dados se têm tirado. Assim, começaremos por dar um breve resumo do funcionamento do sistema nervoso; enunciaremos a seguir os princípios em que assenta a criação dos autómatos electrónicos; depois apresentaremos as comparações entre ambos, para terminarmos. nas críticas que à sua assimilação se possa fazer.

\section{DOUTRINA ACTUAL DO FUNCIONAMENTO NERVOSO}

Os modernos métodos de detecção e amplificação electrónica permitiram verificar que a essência do impulso nervoso que circula através dos vários prolongamentos neurónicos, é um sinal eléctrico, uma diferença de potencial que se propaga com velocidade variável. Seja o conductor nervoso uma via central ou um nervo periférico, o que nêle se regista ao passar a correṇte nervosa é um sinal elécírico. Estes sinais eléctricos tanto se apreciam na neurografia de um nervo, como no EEG ou no electrotalamograma, que registam a actividade de órgãos centrais.

0 primeiro problema que se nos põe, portanto, ao encararmos o funcionamento do sistema nervoso como uma totalidade, é o da origem dêstes sinais eléctricos. Os longos estudos a que se vem procedendo, desde Sherrington e Adrian, levam à conclusão de que êles são conseqüência duma propriedade fundamental dos aglomerados de células nervosas, a sua autoritmicidade. Os neurofisiologistas, nos últimos anos, têm feito neste campo trabalho profundo e valioso, sobretudo comparando os resultados da excitação experimental das células nervosas com a actividade espontânea das mesmas células. Em tal capítulo, Forbes, Fessard, Adrian e muitos outros, produziram trabalho gigantesco, que em muitos pontos esclareceu as nossas dúvidas.

A auto-ritmicidade é a propriedade que têm quaisquer agregados neurónicos de produzirem excitações, as quais se propagam depois a partir dêles. $O$ estudo detalhado da produção destas excitações foi feito pelos neurofisiologistas em determinados núcleos nervosos, particularmente acessíveis. 
Assim, Fessard, por exemplo, estudou-o nos órgãos eléctricos dos torpedos, peixes que produzem descargas eléctricas ao contacto. Fessard verificou que êsse órgão era formado por lamelas, num sentido justapostas e noutro sentido colocadas em série, com terminações nervosas situadas entre as lamelas.

Estudando as excitações partidas dêstes agregados neurónicos por intermédio da ampliação electrónica mais delicada, Fessard pôde demonstrar a existência de impulsões nervosas em séries rítmicas, partidas dêles. A estas impulsões nervosas deu Fessard o nome geral de "pulsações". O seu ritmo caracterìsticamente lento e de ampla voltagem, é influenciado por determinadas condições estimulantes, por exemplo o frio, a acção de certas substâncias químicas, como o cloreto de potássio, a picada, etc., as quais aumentam ainda a sua voltagem. E' estável êste ritmo, e mantém-se autònomamente, independente de qualquer excitação exterior. Para a explicação desta autonomia, tem importância a noção de feed-back, noção a que muitas vêzes me referirei, no decurso desta exposição. Admite-se que a pulsação resultante da auto-motricidade dum agregado neurónico se propague até ao outro agregado seguinte e sofra neste uma forma de reflexão que faz com que uma pulsação em sentido inverso venha alimentar a auto-ritmicidade do primeiro agregado. A esta pulsação em sentido inverso, correctiva ou mantenedora da actividade do primeiro agregado, se chama o efeito de feed-back.

Outro característico das ondas auto-rítmicas colhidas nestas circunstâncias é o seu aspecto ondulatório. Apresentam-se sob a forma de fusos, tal qual como no electrencefalograma humano.

Uma terceira propriedade experimental que tem grande interêsse teórico é a tendência dos çatros pulsáteis vizinhos a trabalharem no mesmo ritmo. As coisas passam-se como se o ritmo dum agregado neurónico tivesse marcada tendência a propagar-se aos agregados vizinhos, e êstes a baterem num sincronismo ou pelo menos num homocronismo favorável à transmissão das pulsações. Assim, as ondas $\alpha$, do ritmo de Berger, podem ser vistas como pulsações autónomas mal sincronizadas com um com. ponente oscilatório do tipo sinusoidal.

A análise destas propriedades gerais permite uma vista de conjunto sôbre o próprio funcionamento dos centros nervosos. Nestes dá-se um afluxo de pulsações vindas dos órgãos periféricos, dos agregados neurónicos situados na periferia do sistema nervoso. Estas pulsações são transformadas nas células e, em conseqüência, lança-se novo fluxo para os órgãos de reacção. Assim, todo o funcionamento do sistema nervoso se limita a uma transmissão e transformação de pulsações entre os agregados neurónicos.

Postas as coisas assim, dum modo geral, três problemas nos ficam agora a discutir, a fim de esclarecermos melhor o propósito que nos ani- 
ma. O primeiro dêstes problemas é o modo de produção das pulsações nervosas; o segundo, o seu modo de acção; o terceiro, a aplicação dos dois anteriores às ondas electrencefalográficas, ou seja, a origem das pulsações geradoras do electrencefalograma.

Ocupemo-nos primeiro do modo de produção das pulsações. Sabemos que em Fisiologia a excitação nervosa é produzida experimentalmente por intermédio da acção duma corrente eléctrica que, segundo a explicação admitida pelos neurofisiologistas, produz no neurónio uma despolarização que se propaga a partir da zona inicial. Esta despolarização experimental é favorecida por certo número de circunstâncias adjuvantes, como sejam: o frio, a presença de sais de potássio, a diminuição da quantidade do cálcio circulante, a presença de pequenas doses de acetilcolina, etc. Todos êstes factores são de molde a facilitar a despolarização provocada pela corrente experimental, e conseqüentemente a formação duma pulsação que, a partir do agregado neurónicó estimulado, se propaga aos outros agregados neurónicos.

Também na natureza os estudos dos neurofisiologistas vieram mostrar que na realidade o fenómeno de excitação nervosa se reduz na sua essência a um processo de despolarização natural. Estes estudos, que é difícil detalhar aqui suficientemente, foram feitos principalmente em agregados neurónịcos de animais elementares, fàcilmente isoláveis, e dos quais se torna muito fácil a recolha das pulsações. Foi, principalmente, o órgão nervoso do ôlho dum certo crustáceo, a límula, que foi estudado por Fessard. Neste órgão nervoso os elementos fotorreceptores estão suficientemente afastados uns dos outros, para ser possível fazer o registo separado das pulsações por êles produzidas.

Adrian, por sua vez, estudou o gânglio óptico do Dyptico, também de registo extremamente fácil. Êste gânglio óptico produz pulsações de amplitude muito acentuada, comparada às do electrencefalograma humano, sendo clássico referir o facto de Adrian ter apresentado um dia um traçado do gânglio óptico do Dyptico em comparação com outro do seu próprio electrencefalograma, entre os quais as diferenças eram escassas.

$O$ estudo dêstes agregados neurónicos fàcilmente isoláveis veio mostrar que a natureza, para obter as pulsações sôbre as quais funda a sinalização nervosa, se serve do mesmo meio que a Fisiologia, ou seja, a despolarização duma porção do neurónio, em geral a sua extremidade receptora.

Qual é a causa inicial, espontânea, desta despolarização? Com efeito, na natureza, os agregados neurónicos podem produzir espontâneamente pulsações, não recebendo prévias excitações, como sucede na estimulação experimental pela corrente eléctrica.

Qual é então a causa inicial, celular, digamos, dêste fenómeno de despolarização espontânea? Aqui, não podemos passar do campo das hipóteses. A mais aceitável é talvez a de que nas células nervosas existam 
mecanismos enzimáticos cíclicos idênticos aos que conhecemos noutras partes do organismo, e que seja o próprio carácter cíclico dêstes processos químicos enzimáticos que produza uma diferença de potencial que não é constante, mas sim intermitente. São bem conhecidos dos fisiologistas os processos enzimáticos que se passam no trabalho do músculo, na respiração, etc., e que apresentam um carácter cíclico, repetindo-se periòdicamente. Do mesmo modo, aceitam alguns neurofisiologistas que processos enzimáticos passados no interior das células nervosas seriam a causa inicial desta pulsação que parte dos agregados neurónicos.

Feita a zona de despolarização, como se faz a pulsação a partir desta zona? Aqui, o processo é inteiramente idêntico ao da despolarização experimental. Há, ao nível da extremidade receptora da célula, uma zona despolarizada que constitui um estímulo para as zonas vizinhas e para o axónio. A despolarização propaga-se por proximidades, através da parede da célula e depois, do seu prolongamento cilindro-axil. A seguir a esta despolarização, há um período refractário que se traduz pela interrupção da transmissão da pulsação. Como conseqüência dêste processo de despolarização, seguida de período refractário e transmitida por continuidade, temos naturalmente produzido o processo da pulsação.

Estabelecida a pulsação do agregado neurónico, analisemos agora o segundo problema, ou seja, o modo de acção desta pulsação sôbre os restantes agregados neurónicos a que ela se transmite. A pulsação partida do neurónio vai perturbar os outros neurónios. Dois efeitos são descritos por Fessard, nesta perturbação: o efeito detonador e o efeito balístico.

O primeiro efeito, o mais evidente, é o efeito detonador, que consiste numa acção despolarizante, imediata e breve, produzida pela pulsação transmitida, e que é afinal análogo à propagação intraneurónica. No segundo agregado neurónico que recebe a púlsação dá-se como que uma detonação na formação brusca duma despolarização, cuja descarga, por sua vez, vai constituir uma nova pulsação.

O segundo efeito não é menos importante do que êste. E' o que Fessard chama o efeito balístico ou acção polarizante. A célula nervosa encontra-se num estado de polarização que predispõe para que, quando recebe a pulsação transmitida por outra célula, se dê nela uma imediata despolarização. Esta acção polarizante constitui o efeito balístico das pulsaçóes e é formada por uma série de fenómenos, sobrevivendo muito tempo ao abalo inicial, produzido pela pulsação anterior. Estas alterações, quer de natureza química, quer de natureza física, criam na célula, atingida por êste efeito balístico, um estado de excitabilidade que se pode comparar ao estado do tono dos músculos, quer dizer, uma predisposição para a descarga ulterior. Cria-se, assim, a situação de polarização, e a nova pulsação vem encontrar um limiar provàvelmente abaixado, propício à descarga despolarizante. 
Este afluxo constante de pulsações convergentes que incidem sôbre cada uma das células nervosas, cria um estado central de excitação que por sua vez é o gerador responsável pelas novas pulsações que vêm ulteriormente estabelecer-se. A despolarização central que resulta dêste efeito balístico prolonga a negatividade detonadora, e deve ser considerada, como diz Fessard. como um agente de relayage, isto é, agente de ligação.

Fessard insiste muito sôbre o papel das pulsações, na redistribuição selectiva, propriedade que êle considera a função essencial do sistema nervoso. Com efeito, as pulsações não se transmitem desordenadamente através dos conductores centrais e periféricos. Distribuem-se antes selectivamente, isto é, pulsações da mesma natureza, com a mesma função, unem-se, não se dispersam.

Este facto, que Fessard denomina de redistribuição selectiva, é devido ùnicamente à acção das pulsaçõès nervosas. Estas, por um lado, vão produzir novas reacções nervosas, em parte devidas à acção da pulsação recebida, em parte função do estado de excitação central de cada célula; por outro lado, pelos seus parámetros - quer dizer, pelas suas grandezas físicas (freqüência e intensidade variáveis) - elas agrupam-se e graduam finamente os seus efeitos. Podem assim ser consideradas como os agentes mais importantes da selectividade, a qual, por sua vez, é a propriedade fundamental do tecido nervoso. Pulsações dos mesmos parámetros tendem provàvelmente a agregar-se $\mathrm{e}$ a transmitir-se pelas mesmas vias, incidindo sôbre os mesmos agregados neurónicos.

A especificidade do sistema nervoso fica assim reduzida a um fenómeno de natureza puramente física. A partir desta concepção, muitas idéias se explicam: a convergência das excitações da mesma natureza num "final common path", como queria Sherrington, a teoria do isocronismo de Lapicque, baseada sôbre a afirmação de que a transmissão se daria apenas entre elementos do mesmo valor cronáxico, na qual haveria a fazer a correcção de que a função cronáxica não estaria na própria célula, mas nos parámetros das pulsações que através dela são transmitidas.

Podemos agora, com estas breves idéias acêrca da pulsação e da transmissão de sinais no sistema nervoso, chegar ao terceiro problema, ou seja, o ponto de origem das pulsações do electrencefalograma humano.

Três doutrinas se nos apresentam, tôdas elas fundadas em concepções muitas vêzes difíceis de compreender, exigindo conhecimentos rádio-eléctricos e matemáticos, que não estão freqüentemente ao alcance dos clínicos. Em qualquer delas, as ondas do electrencefalograma são afinal uma soma algébrica dos diferentes potenciais de acção. Como se sabe, muitos milhổes de células, 174 milhões, segundo os cálculos de Gellhorn, se encontram distribuídas ao nível do córtex. As ondas do electrencefalograma não seriam mais do que o integral da actividade eléctrica dêstes $171 \mathrm{mi}$ lhões de células nervosas. 
Convergindo em considerar as ondas electrencefalográficas como a soma algébrica de diferentes potenciais de acção, as três teorias que tentam a explicação do electrencefalograma humano divergem na consideração dos agregados neurónicos dominantes na criação do ritmo referido.

A primeira teoria aceita que as ondas cerebrais são devidas à autoritmicidade dos agrupamentos corticais, necessitando, para se exteriorizarem, dum mínimo de afluxos centrípetos, mas provenientes ùnicamente da própria acção dos agregados neurónicos situados no córtex.

A segunda teoria admite, pelo contrário, que as ondas corticais resultam da estimulação do córtex inerte, por ondas rítmicas vindas dum pacemaker talámico. Pace-maker é um centro regulador do ritmo imprimido a outra zona. Assim, existiria um pace-maker ao nível da parte mais alta do tronco cerebral, a que Penfield chama hoje "niger brain stem", e èste pace-maker seria o responsável pela produção dum ritmo cortical traduzido nas ondas $\alpha$.

A terceira teoria aceita que o ritmo recolhido do electrencefalograma resulta da passagem periódica de ondas em circuito, ondas que, incessantemente, circulariam entre o tronco cerebral (principalmente a sua parte mais alta), o tálamo e o hipotálamo, e o córtex por outro lado. Esta teoria, defendida hoje por numerosos fisiologistas, a teoria dos "reverberating circuits", tem um interêsse muito grande pelas conseqüências teóricas a que deu lugar, e por ser sôbre ela que em grande parte se baseiam as comparações cibernéticas.

E' impossível, digamo-lo desde já, decidir no momento actual por uma das teorias em causa. E' até provável que tôdas elas contenham uma parte da verdade. $O$ que, porem, mais interessa para o ponto de vista que encaramos nesta conferência, é que a terceira teoria, a dos circuitos reverberantes, pode considerar-se como experimentalmente comprovada, o que faz aparecer aos nossos olhos o sistema nervoso como um complexo de circuitos, nos quais incessantemente circulam sinais eléctricos.

O sistema nervoso é, pois, um vasto agregado de elementos neurónicos, cêrca de $10^{10}$, dotados da capacidade de produzir, transformar ou transmitir pulsações. Estas pulsações circulam numa vasta rêde de conductores de sinais eléctricos, selectivamente encaminhados. E tudo o que em nós constitui idéia, memória, comportamento ou acção, resulta da orientação e natureza dêsses sinais eléctricos que representam a actividade nervosa e que incessantemente circulam em órbitas determinadas.

\section{TEORIA DOS AUTÓMATOS}

Começaremos por salientar que aquilo que se segue não será mais do que uma breve e muito sumária lição sôbre a teoria dos autómatos em geral, e das máquinas de calcular, em particular. Para uma exposição 
mais profunda faltam-nos por completo os conhecimentos de física e matemática que para tal seriam indispensáveis.

Baseiam-se as máquinas de calcular em um de dois princípios fundamentais, o da analogia, e o digital ou lógico.

No primeiro, os números são representados por certas quantidades físicas e as operações decorrem entre estas. Tais quantidades podem ser o número de graus de um arco de disco, a intensidade de uma corrente eléctrica, ou a extensão de uma diferença de potencial. Introduzidos os valores na máquina, esta, por métodos diversos, executa a sua adição ou a sua multiplicação. E', no seu aspecto mais simples, a black-box à qual se fornecem duas correntes e que distribui uma corrente igual ao seu produto. As máquinas fundadas no princípio da analogia, foram as primeiras imaginadas, mas são as mais imprecisas pelo grau elevado de flutuações incontroláveis e o seu uso é limitado também pelo número escasso de operações totais executáveis.

O princípio digital representa os números por um agregado de dígitos. Dois sistemas de notação se empregam, um mais antigo, o sistema decimal, de base 10, outro mais recente, e cuja importância avulta nas comparações com o funcionamento do sistema nervoso, o sistema binário. No primeiro, os números são representados por dez sinais diferentes, correspondendo aos dígitos de 0 a 9 . 0 segundo sistema, porém, funciona na alternativa do 0 ou do 1 , todos os números sendo representados por um conjunto de eventualidades positivas ou negativas. Assim, 1, 2, 3, 4, 5, serão, por exemplo, $1,10,11,100,101$, etc.

A comparação entre a transmissão dêstes sinais e a das pulsações nervosas, obedecendo, como vimos, no capítulo anterior, à lei de tudo ou nada, é flagrante.

Nas máquinas construídas segundo o princípio digital, um sinal electrónico percorre o circuito, indicando os números pela série de vêzes que passa. O que caracteriza, pois, o mecanismo digital (ou lógico como também é chamado), é que os seus estados possíveis estão nìtidamente separados. No caso mais simples, o dos mecanismos binários, tudo decorre numa alternativa de sim ou não, de 0 ou 1 . A máquina tem um certo número de circuitos electrónicos. Recebe uma informação que transforma em sinais e fornece uma nova informação, expressão dos sinais que atingem a saída. A relação entre a informação que entra (input) e aquela que sai (output), é chamada, por McCulloch, a corrupção.

Entre a entrada das informações e a sua saída, decorre uma enorme série de combinações de circuitos electrónicos, feita a grande velocidade, cruzando numerosos dispositivos de comutação que são válvulas electrónicas, os quais dão sucessivamente uma resposta de ligado ou desligado, isto é, de $\operatorname{sim}$ ou de não. 
As combinações dos circuitos fazem-se a partir dos dados fornecidos na ocasião e de outros, já registrados anteriormente e armazenados pela máquina, que figuram como sendo a sua memória.

As modernas máquinas de calcular têm diversas espécies de memória. A mais simples, é a formada de ligações, constituindo um circuito fechado, de comprimento suficiente para que os trens de sinais se não atropelem uns aos outros. Neste circuito, um determinado modêlo de arranjo de sinais pode circular indefinidamente, entrando nas combinações quando para isso é solicitado.

Outros tipos de memória das máquinas, são os constituídos pelos tanques acústicos, pelos tubos de raios catódicos com écrans de diversas persistências, semelhantes aos da televisão, onde o sinal subsiste um certo tempo, e outros ainda mais complexos. A extensão destas memórias electrónicas é já hoje muito grande. Como exemplo, dir-lhes-ei que uma das mais completas máquinas de calcular, o Ferranti Mark I Computer, da Universidade de Manchester, tem a capacidade de armazenar mais de 33.000 números da ordem do milhão, ou 16.000 da ordem do trilião. Também a agilidade dêstes órgãos de memória é notável, permitindo encontrar instantâneamente o dado necessário.

Um princípio basilar no funcionamento e integração das máquinas de calcular é o de feed-back negativo, a que já atrás, a propósito do exemplo do canhão anti-aéreo, me referi. Uma parte da produção de cada circuito retorna à origem e regula a sua produção ulterior, corrigindo o êrro e contribuindo para a automatização e indefinido funcionamento do sistema.

Êste princípio do feed-back, introduzido por Wiener, Bigəlow, Rosenblüth e outros, é decisivo, porque é êle que corrige a margem de êrro a que o objecto se encontra, em relação ao objectivo específico proposto. $\mathrm{Na}$ sua última obra, Wiener define-o dizendo que o princípio de feed-back significa que o comportamento é regulado pelo seu resultado, e que o sucesso ou insucesso dêste resultado modifica o comportamento futuro. Assim, o feed-back fornece experiência e constitui aprendizagem. E' o contrôle da máquina na base do resultado actual e não do resultado esperado, envolvendo a presença de membros sensoriais, que são actuados pelos motores e exercem por sua vez a função de monitores daqueles. A máquina moderna contém, pois, um certo elemento de aprendizagem, baseando-se na passada experiência para modificar o conjunto total do seu comportamento.

Também os mecanismos de feed-back representam importante papel na correcção de uma outra noção sôbre a qual ùltimamente insiste Wiener, a de entropia. De acôrdo com a famosa segunda lei da termodinâmica, um sistema pode espontâneamente perder ordem e regularidade, mas pràticamente nunca a pode ganhar. A medição desta perda de ordem (ou desor- 
dem) é um número logarítmico inverso, e é o que constitui a entropia, a qual, como é lógico, nunca pode diminuir num sistema isolado. $O$ princípio do feed-back constitui o mais importante factor que se opõe à progressiva desordem da máquina, isto é, ao aumento da sua entropia, pelos elementos de correç̧ão e automatismo que introduz nos seus circuitos.

Funcionando nestas bases, a máquina, de acôrdo com as regras da lógica e da matemática, manobra os dados que lhe são fornecidos em séries de eleições entre duas alternativas, fazendo intervir nas eleições actuais os elementos recordados das eleições passadas. Milhares de operações são efectuadas a velocidades prodigiosas que atingem, por exemplo, no caso de Mark I, a média de 3 milhões de cálculos por hora. E tudo se passa sem qualquer interferência humana.

A máquina moderna executa tôda a espécie de cálculos, adapta-os e transmite-os aos objectivos materiais por ela regulados (caso, por exemplo, do predictor do canhão anti-aéreo) e é capaz até de jogar e ganhar contra seres humanos partidas de determinados jogos. O Ferranti Nimrod, que estava na Exposição de Londres em 1951, além de tôda a casta de operações matemáticas, feitas quase instantâneamente, com uma percentagem de erros muito inferior à que qualquer equipe humana poderia obter, ainda jogava com o público um determinado jôgo de cálculo, o Nim, no qual ganhava quase sistemàticamente. E' de admitir também a próxima existência de máquinas que joguem o xadrez, já sem aquêle artifício fraudulento que Edgar Poë descobriu no famoso autómato jogador de xadrez de Maelzel, que continha no seu interior um aleijado sem pernas.

E o autómato criado pelo matemático inglês Booth, que não só resolve tôda a espécie de cálculos, como ainda faz traduções para quatro ou cinco línguas, é talvez o mais aperfeiçoado dos autómatos até hoje criados.

A complicação e o progressivo aumento de possibilidades dêstes cérebros electrónicos leva Wiener - o mágico que tem projectado vários dêles - a admitir que por seu intermédio seja possível a substituição da quase totalidade do trabalho industrial do homem; que seja possível, com a sua produção em massa, eliminar os operários das grandes fábricas de automóveis e substituí-los por mecanismos servo-comandados que escolhem e adaptam as peças que constituem o veículo.

Os problemas sociais suscitados pelo advento dêstes verdadeiros robots, que Wiener, animado pelo mesmo espírito humanitário de Leonardo da Vinci, encara no seu último livro, são incalculáveis e constituem talvez uma nova revolução social que até há pouco se não podia prever. Se se chegou já até ao ponto de admitir um mundo no qual os autómatos, desenfreados, eliminassem os seres humanos e passassem a viver automática $\mathrm{e}$ indefinidamente!

Nas palavras que vimos de pronunciar, mais não fizemos do que dar uma rápida e incompleta idéia do problema vastíssimo da teoria, funcio- 
namento e possibilidades dos autómatos ou mecanismos servo-comandados. $\mathrm{O}$ detalhar mais semelhantes questões, exigiria muito tempo e competência, de que não dispomos.

Pretendemos, entretanto, não encerrar esta parte da nossa exposição sem nos referirmos a certas semelhanças existentes entre o comportamento dos autómatos e o das criaturas vivas. Escolheremos para isso o mais simples dos autómatos, a Machina Speculatrix ou tartaruga electrónica, realizada pelo ilustre neurofisiologista de Bristol, Grey Walter, precisamente com o objectivo de demonstrar essas semelhanças.

As tartarugas de Grey Walter figuraram na Exposição Britânica do ano último e muitos dos presentes seguramente observaram o seu estranho comportamento. Eram esquemàticamente constituídas por dois circuitos, duas baterias e dois receptores, uma célula fotoeléctrica que os sensibilizava para a luz, e um sensível contacto eléctrico, que servia como receptor táctil. Estes robots deslocavam-se, procurando a luz; se tocavam em algum obstáculo, afastavam-se e contornavam-no, e quando as suas baterias careciam de carga, dirigiam-se para o estaleiro onde estava o acumulador que lhes fornecia essa carga.

Uma análise detalhada do comportamento dêstes autómatos rudimentares, levou Grey Walter a atribuir-lhes os seguintes princípios, comuns aos seres vivos: 1) parcimonia, quer dizer, economia de estructura e função, que lhe permite, a despeito de uma estructura sumária, uma grande variedade de modelos de comportamento; 2) tendência especulante, isto é, propensão à exploração do ambiente, a máquina mantendo-se incessantemente em movimento, como se reconhecesse os locais; 3) tropismos positivos $e$ negativos, o primeiro para as luzes de média intensidade, os segundos para os obstáculos mecânicos e para as luzes excessivamente brilhantes; a tartaruga comporta-se como se estivesse constantemente perscrutando em volta os seus tropismos; 4) discernimento, que permite ao autómato, quando atraído pela luz e desde que encontre no seu caminho um obstáculo, eliminas o seu tropismo positivo para aquela, em favor do tropismo negativo do contacto, que lhe permite contornar o obstáculo, e só depois tomar a direcção da luz; 5) tendência para o óptimo. que leva a máquina a procurar as condições mais favoráveis: quando está colocada entre duas luzes iguais, a máquina não segue o dilema do burro de Buridan, que hesitava entre dois montes de feno e morria de fome, dirige-se antes primeiro para uma das fontes luminosas e depois para a outra; 6) auto-reconhecimento, a máquina extinguindo o seu próprio farol ao chegar junto de um espelho onde êle se reflicta, para o acender de novo ao afastar-se, descrevendo assim uma dança que tem seu quê de imagem de Narciso revendo-se no espelho das águas; 7) reconhecimento mútuo, duas tartarugas tendo uma com a outra um comportamento constante, procurando-se quando os seus farois se vêem, apagando êstes mal chegam ao contacto e evitando-se como obstáculos se se encontram de lado ou por detrás; 8) 
por último, a estabilidade interna dos circuitos, que leva a tartaruga a buscar a carga quando essa estabilidade começa a ser alterada.

Não deixa de ser perturbante êste feixe de analogias entre o comportamento de um autómato tão simples e o dos seres vivos, mais ainda se se pensar que o constructor de tais autómatos só depois de os ter realizado é que observou nêles semelhantes analogias.

\section{O SISTEMA NERVOSO COMO MAQUINA DE CALCULAR}

São de Mac Culloch, matemático e físico, vindo até à psiquiatria pelo seu interêsse por êstes problemas, e hoje professor eminente de psiquiatria em Chicago, as mais sensacionais afirmações no que refere às comparações entre o cérebro e as máquinas de calcular. Estas comparações têm, como acabamos de ver da análise sumária do funcionamento de uns e outros, fundamentos bastante sugestivos.

Cérebro e máquinas de calcular são dispositivos onde se originam e circulam sinais. Estes não são apenas influxos eléctricos propagados, mas têm na sua essência a proposta de qualquer coisa. $O$ sinal é verdadeiro se o que êle conclui dever suceder, sucede. De outro modo é falso, como sucede no caso do sistema nervoso, com as parestesias ou as alucinações. Dêste modo, o sinal possui as propriedades mentais lógicas, de uma proposição; é pois, por definição, uma proposição materializada num processo físico.

O cérebro, diz Mac Culloch, é a mais complicada máquina de calcular do tipo lógico ou digital. E' um conjunto de 10 bilióes de relays — os neurónios - funcionando quase independentemente, e oscilando apenas en. tre dois estados, pulsação ou não pulsação.

Cada uma destas células conserva no seu exterior um décimo de volt positivo em relação ao seu interior, até ser excitada. Quando isto sucede, a corrente das zonas positivas da célula estende-se às negativas, e a pul. sação, como um anel de fumo, vai ocupando tôda a célula e os seus prolongamentos. A velocidade com que a pulsação se propaga é função do calibre dos conductores, das resistências e da fonte de voltagem da célula nervosa; esta velocidade varia entre $150 \mathrm{e} 0,30 \mathrm{~m} / \mathrm{seg}$. A existência de um tempo de latência variável entre a chegada do impulso à célula e a partida da sua pulsação, faz com que o número de trens de pulsaçôes por segundo seja variável. Este número pode atingir 200 pulsações por segundo, mas habitualmente anda à roda de 20 .

Se compararmos agora as células nervosas com os relays das máquinas electrónicas, vemos que elas são mais rápidas do que os contactos electromagnéticos, mas que têm cêrca de um milésimo da rapidez da resposta das válvulas de vácuo, hoje geralmente usadas. O seu tamanho, porém, é infinitamente mais pequeno do que o das válvulas de vácuo e o consumo 
de energia, infinitamente menor. Mc Culloch calculou que, se se pretendesse construir um autómato electrónico com tantos relays como neurónios tem a máquina cerebral, seria preciso, para lhe fornecer energia, todo o poder das quedas de água do Niagara, para a sua refrigeração a própria corrente do Niagara, e o seu volume exigiria um edifício maior do que qualquer dos que no mundo existem. Eniac, a maior máquina de calcular existente, com 10.000 válvulas, não chega a ter o número de relays que tem o sistema nervoso de uma minhoca!

Vejamos agora as analogias entre os princípios funcionais dos mecanismos servo-comandados, que expusemos há pouco, e os da fisiologia nervosa.

Os exemplos de funcionamentos automáticos por circuitos de feed-back, existentes no organismo humano, são numerosos, e a sua semelhança com os mecanismos servo-comandados é flagrante. Vamos apresentar alguns. A regulação nervosa da tensão arterial faz-se automàticamente pelo seguinte mecanismo: o aumento da tensão traz como conseqüências imediatas uma dilatação da aorta ascendente, donde parte o nervo depressor de Ludwig Cyon, e um aumento da excitação que normalmente recebe da onda sangüínea o seio carotídeo, situado na bifurcação da carótida. Estes estímulos são conduzidos aos núcleos vegetativos do bulbo raquidiano pelo IX par craniano para o primeiro, e pelas fibras simpáticas para o segundo, funcionando estas fibras partidas do nervo de Cyon e do seio carotídeo como circuitos de feed-back informativos. Dos núcleos do tronco cerebral partem então duas ordens de circuitos, uns imediatamente correctivos, e a sua conseqüência é o relentamento do pulso e a dilatação dos pequenos vasos periféricos e do território esplâncnico, destinados a lutar contra o aumento da tensão; outros ainda, informativos, destinados aos núcleos diencefálicos. Dêstes partem novos circuitos correctivos, actuando provàvelmente em especial na secreção hipofisária, e tendo como conseqüência a libertação duma hormona hipopressora, lançada em seguida na circulação. Há, como se vê, evidentes semelhanças entre esta auto-regulação tensional e a regulação automática do tiro anti-aéreo.

Outro exemplo, referido agora a uma função motora e citado por Gastaut, é o da regulação dos movimentos voluntários. Estes são resultantes de excitações que têm a sua origem no córtex motor, que se transmitem pela via piramidal até às células motoras dos cornos anteriores e que têm o seu último agente efector na placa mioneural. Ora, êste circuito principal tem, pelo menos, dois circuitos de auto-regulação inversa correctiva, cujo funcionamento é indispensável à exacta composição do movimento a efectuar. São êles um circuito córtico-ponto-cerebelo-rubro-tálamo-cortical e outro mio-espino-cerebelo-espino-muscular. A supressão de qualquer dêstes circuitos tem graves conseqüências sôbre a execução dos movimentos, que se torna imprecisa e deixa de atingir a sua finalidade, gerando-se assim o sintoma ataxia. Os exemplos de mecanismos auto-reguladores dêste 
gánero multiplicam-se na fisiologia humana e podemos dizer que é a estabilidade de tais mecanismos que torna a vida possível. A esta estabilidade das auto-regulações dá Ashby o nome de homeostase.

A comparação com os mecanismos auto-comandados não se limita, porém, às funções orgânicas, pois se estende também às próprias funções psíquicas. A comparação mais flagrante neste aspecto é a da memória, com as máquinas de calcular. Há, efectivamente, uma evidente semelhança entre a memória da máquina de calcular, especializada, mas perfeitíssima, e a memória humana, sendo razoável a concepção dos neurofisiologistas, que vêem esta como resultante também de mensagens circulando indefinidamente em circuitos cerebrais auto-mantidos.

Uma outra comparação do mesmo género, também bastante feliz, é a que diz respeito aos processos de reconhecimento visual e ao mecanismo da televisão. Nesta, o feixe luminoso do iconoscópio percorre a retina eléctrica ponto por ponto, num certo sentido (balayage), para se apoderar da cena a transmitir. No cérebro humano, segundo Mc Culloch, o pulvinar, por intermédio dos circuitos occipito-pulvinários, faria também uma exploração sistemática, ponto por ponto, do córtex occipital, transformando assim em sinais temporais os sinais puramente espaciais que a "retina" cortical receberia da retina ocular. Esta transformação seria necessária para que nós pudéssemos ter consciência da imagem recebida, visto que nada para nós se pode fazer fora do tempo (Mc Culloch).

A consciência da percepção, por sua vez, só poderia ser adquirida depois desta reverberação do córtex para o tálamo. Neste ponto, os cibernéticos filiam-se na mesma doutrina há pouco defendida por Penfield, que situa o nível da consciência no "higher brain stem", em que compreende os núcleos cinzentos situados acima do sulco pedúnculo-protuberancial e abaixo do córtex.

0 reconhecimento da configuração (Gestalt) e a identificação do objecto percebido seriam funções comparativas: nos milhares de circuitos reverberantes tálamo-occipitais, uns levariam a nova percepção, mas os outros continuariam fazendo circular em eco os dados já anteriormente percebidos, permitindo assim a comparação e o reconhecimento da nova imagem adquirida. A descoberta por Kubie e Lorente de Nó, de circuitos reverberantes permanentes ao nível do sistema nervoso, confirmada depois por outros neurofisiologistas, veio trazer uma importante confirmação a estas deduções teóricas.

E' possível e tem grande interêsse, o estabelecimento de comparações entre a patologia humana e a das máquinas de calcular. Estas são também susceptíveis de "adoecer", sendo as suas doenças designadas grimsles.

Qualquer sistema de circuitos eléctricos pode apresentar-se em três estados: a estabilidade, o estado oscilatório e a instabilidade. A estabilidade, posição ideal do sistema, mantém-se em certo tempo, mas não pode 
manter-se indefinidamente. Alguns dos circuitos começam então a oscilar, entrando em instabilidade e deixando, por fim, de transmitir em eco o sinal que lhes compete. Segundo Wiener, podem então tratar-se êstes circuitos doentes por três processos, que têm flagrante comparação com a patologia humana: 1) dar à máquina um período de repouso, findo o qual muitas vêzes os circuitos avariados se recompõem por si próprios; 2) aplicar-lhe uma corrente eléctrica forte (electrochoque...), que em muitos casos recompõe os circuitos alterados; 3) se não há possibilidade de cura, desconectar os circuitos alterados, ficando apenas a trabalhar a restante parte da máquina (lobotomia...). Grimsles e neuroses, diz Mc Culloch, são demónios que se introduzem nos circuitos...

Muitas são as deduções comparativas que se podem retirar dêstes factos, no que se refere à patologia humana, quase tôdas elas, porém, de natureza teórica e por ora sem fundamentos reais. Mas não há dúvida que a doutrina da constituição do sistema nervoso a partir dos circuitos reverberantes, que os cibernéticos defendem, vai tendo cada vez mais adeptos e está cheia de promissoras comparações. $O$ essencial passará agora a ser a unidade funcional constituída pela área cortical, o núcleo talâmico e o circuito que os liga; e os sintomas deverão ser os mesmos em qualquer ponto onde o circuito seja atingido. Por isso, Hassler propóe que a patologia cerebral seja revista, à luz desta nova e ousada concepção.

\section{CÉREBRo HUMANO E MAQUINAS CEREBRAIS}

Chegados a esta altura da nossa exposição - muito embora sumária - uma idéia avulta com nitidez crescente, a de que a máquina, progressivamente mais perfeita, se aproxima cada vez mais do paradigma que visa, o do cérebro humano. Em alguns aspectos mesmo, consegue até ultrapassá-lo. Cérebro algum de homem possui, com efeito, a capacidade de trabalhar simultâneamente milhares de dados elementares, dispersando sôbre êles uma gigantesca atenção difusa, como Eniac e os seus irmãos autómatos.

E quê dizer da espantosa rapidez com que êsses milhares de cálculos são executados, fornecendo os resultados em milésimos de segundo? Até mesmo se poderá dizer que a missão altruista de certas máquinas iguala a dos mais generosos homens: se Louis Braille inventou um método de leitura para cegos, a máquina electrónica que Wiener descreve no seu último livro, que lê os textos tipográficos por um mecanismo semelhante ao da televisão, transformando-os em percepções tácteis cujos sinais permitem uma nova forma de leitura, não fica atrás, em concepção humanitária, do método do famoso filântropo de há cem anos.

Até na possibilidade de uma reprodução similar poderia a máquina ser superior ao homem. Neuman admite que os autómatos possam criar, espontâneamente, novos autómatos iguais, não atreitos às mutações desfa- 
voráveis e aos fenómenos degenerativos que inferiorizam tanto o género humano.

Esta nova ciência das comunicaçôes, aproximando cada vez mais o cérebro das máquinas, e conseqüentemente o pensamento de um jôgo regrado de sinais, criando, na frase já citada de Mc Culloch, a ponte entre a psique e o soma, traz dentro de si uma nova concepção filosófica materialista e até mecanicista que importa analisar brevemente. Como sucedia no auge das concepções de Pavlov, quando o cérebro era tido por um vasto analisador de reflexos condicionados, e a conducta por um conjunto de condicionamentos aprendidos, chegamos agora ao extremo de ver o cérebro como "a perfect digital computing machine" e o espírito como o producto fatal das interações pré-estabelecidas dos seus circuitos reverberantes.

Contra esta concepção, que mostra uma alarmante tendência à extensão, vão dirigir-se as nossas últimas considerações. Não envolvem elas menos admiração pelo extraordinário progresso que representa a constante criação dos mecanismos automáticos e, sobretudo, pelo objectivo altruísta que a êles preside, ajudando o homem a suportar melhor o fardo da vida. Tão simplesmente, a necessidade de salientar que entre os autómatos criados pelo homem e êle próprio, existem diferenças fundamentais, que não permitem deduzir da existência e perfeição daqueles, uma doutrina filosófica explicativa dos problemas espirituais dêste.

A primeira diferença fundamental e que naturalmente salta logo ao espírito de todos, é a de que a máquina não pode resolver mais do que determinada categoria e certo número de problemas para os quais foi criada. Move-se e actua dentro de um âmbito determinado, fora do qual. por maior que êle seja, lhe não é permitido sair. O pensamento humano, pelo contrário, dispõe de possibilidades muito maiores: pode não ser capaz de resolver, com a precisão e no número com que a máquina o faz, certos problenıas ou cálculos matemáticos, mas é sempre capaz de resolver outros problemas além dos que esta já resolve, e até de os criar. Podemos opor à rigidez dos autómatos, funcionando em circuitos estereotipados, a plasticidade do funcionamento mental do homem, tendo sempre, além de tôdas as conductas que the conhecemos, mais um sem número de infinitas e inesperadas possibilidades.

Uma diferença fundamental que muito hem salienta Dubarle é a de que a máquina, seguindo a definição escolástica de dedução, procede do geral para o particular, dentro de um invariante de possibilidades, no qual ela não é capaz de introduzir qualquer elemento novo. $O$ espírito, pelo contrário, alarga sempre êste horizonte de possibilidades, criando soluções diferentes daquelas que the impõem os sinais que circulam nos circuitos reverberantes da máquina.

Porque - outra diferença - a máquina limita-se a fornecer automàticamente um resultado que lhe foi pré-determinado, enquanto o pensa- 
mento do homem, para chegar a êsse resultado, tem de partir da sua formulação simbólica, equação ou fórmula, cujo desenvolvimento contém em si a própria essência da inteligência.

Por mais perfeitos e aproximados que tenham sido os cálcu'os de probabilidades que informam o autómato, o espírito humano encontra sempre uma subtileza que o cálculo não havia alcançado e que vence a máquina. Serve isto, por exemplo, para as máquinas de jogos de estrategia, baseadas nos estudos matemáticos, de Neumann, e até para o predictor do canhão anti-aéreo, que procura contrapor a exactidāo do seu tíro às subtilezas do piloto, mas que êste, se conhecer os segredos dos circuitos em que êle funciona, consegue iludir.

Existe, pois, uma parte puramente mecânica do pensamento humano, que os autómatos podem suprir, excedendo-a até em perfeição. Mas a outra parte da inteligência do homem, a que cria e critica, a que inventa e escolhe, essa permitir-lhe-á sempre estar acima da máquina, ser o seu criador e ser por ela inimitável. Essa parte é a verdadeira inteligência do homem, a que tantos têm procurado definir, a que Halstead tenta agora analisar matemàticamente, mas que afinal consegue escapar sempre a tôdas as análises e definições, porque, usando a frase do grande Sherrington, "goes more ghostly than ghost".

À luz dela, são pueris as mais científicas comparações do cérebro e da máquina, são primitivos os receios de que um universo de autómatos possa dominar a inteligência humana, essa acima da qual existe apenas a determinação do Criador.

Av. Casal Ribeiro, 12 -- Lisboa - Portugal. 